\title{
A pilot study assessing social support among cancer patients enrolled on clinical trials: a comparison of younger versus older adults
}

This article was published in the following Dove Press journal:

Cancer Management and Research

26 May 2010

Number of times this article has been viewed

\author{
Paul J Novotny' \\ Denise J Smith' \\ Lorna Guse ${ }^{2}$ \\ Teresa A Rummans ${ }^{3}$ \\ Lynn Hartmann ${ }^{4}$ \\ Steven Alberts ${ }^{4}$ \\ Richard Goldberg ${ }^{5}$ \\ David Gregory ${ }^{6}$ \\ Mary Johnson ${ }^{7}$ \\ Jeff A Sloan'
}

'Health Sciences Research, Mayo Clinic, Rochester, MN, USA; ${ }^{2}$ Faculty of Nursing, University of Manitoba, Winnipeg, Manitoba, Canada;

${ }^{3}$ Psychiatry, Mayo Clinic, Rochester, MN, USA; ${ }^{4}$ Medical Oncology,

Mayo Clinic, Rochester, MN, USA; ${ }^{5}$ Oncology Services, University of North Carolina, Chapel Hill, NC, USA; ${ }^{6}$ Faculty of Health Sciences Nursing, University of Lethbridge, Lethbridge, Alberta, Canada; ${ }^{7}$ Chaplain Services, Mayo Clinic, Rochester, MN, USA
Correspondence: Paul J Novotny

Division of Biostatistics

Department of Health Sciences Research 200 First Street SW

Rochester, MN 55905

Tel +1 507-284-4I86

Fax+1 507-266-2477

Email novotny@mayo.edu
Purpose: This study tested the logistical feasibility of obtaining data on social support systems from cancer patients enrolled on clinical trials and compared the social support of older adults (age $\geq 65$ ) and younger adults ( $<50$ years of age) with cancer.

Methods: Patients had to be eligible for a phase II or phase III oncology clinical trial and enter the study prior to treatment. Patients filled out the Lubben Social Network Scale (LSNS) at baseline. The Symptom Distress Scale (SDS) and single-item overall quality of life (QOL) Uniscale were assessed at baseline and weekly for 4 weeks.

Results: There was no significant difference in overall mean Lubben social support levels by age. Older patients had more relatives they felt close to ( $85 \%$ versus $53 \%$ with 5 or more relatives, $P=0.02$ ), heard from more friends monthly ( $84 \%$ versus $53 \%$ with 3 or more friends, $P=0.02)$, less overall symptom distress $(P=0.03)$, less insomnia $(P=0.003)$, better concentration $(P=0.005)$, better outlook $(P=0.01)$, and less depression $(P=0.005)$ than younger patients.

Conclusions: Younger subjects reported worse symptoms, a smaller social support network, and fewer close friends and relatives than older subjects. Having someone to discuss decisions and seeing friends or relatives often was associated with longer survival.

Keywords: social support, Lubben scale, QOL, elderly

Approximately 10.1 million individuals in this country have a history of cancer and $1,372,910$ new individuals were diagnosed in the year 2006. The prevalence of cancer is about $13 \%$ in patients $18-49$ and about $60 \%$ in ages 65 or over. ${ }^{1}$ Receiving a cancer diagnosis affects individuals in a multitude of ways. It is critical for cancer patients to have support, especially in light of the fear and social 'stigma' of cancer. ${ }^{2}$ The availability of support may decrease as a result of these issues and social networks of older people tend to be smaller than those of younger individuals. ${ }^{3,4}$ In previous studies in noncancer cohorts, better social support has been linked to longer survival times, ${ }^{5,6}$ lower hospitalization rates, ${ }^{7}$ better adjustment after diagnosis of disease, ${ }^{8}$ and better retention of cognitive function. ${ }^{9}$ More research is needed on the impact of social networks among cancer patients.

Studies have reported the positive effects of social support at the time of diagnosis and during adaptation to the disease. ${ }^{10-16}$ Conversely, cancer patients with diminished emotional support report more symptoms and lower QOL. ${ }^{14,17}$ Cancer patients have unique social support issues. For them, support from a spouse, immediate family, and peers are critical. ${ }^{15,18}$ The fear associated with cancer diagnosis and treatment increase the need for support, ${ }^{14,19}$ while at the same time the social stigma of having cancer can decrease the availability of support when it is most needed..$^{14,20,21}$ Social 
support models must be tailored to fit the specific needs of the individual because social support needs vary by treatment and stage of disease. ${ }^{11,14,16,22}$

The primary goal of this pilot study was to gain experience with assessing social support in cancer patients. This experience will lead to further studies of social networks in this cohort. The research hypotheses for this study were that the level of social support diminishes with age and has an impact on secondary goals. These secondary goals included symptoms captured by the SDS, mortality, and overall QOL.

\section{Methods}

\section{Study design}

The present study was a prospective, non-randomized cohort design. The accrual goal was 30 patients in each group. This sample size would provide $80 \%$ power to detect a difference of 0.7 of a standard deviation between the two groups. This effect size is considered a moderate to large effect size. ${ }^{23}$ Completion rates were calculated, with $80 \%$ completeness as a criterion for acceptability for further study.

\section{Patients}

This study was approved by the Mayo Foundation Institutional Review Board and participants provided informed consent. Patients had to be eligible for a Mayo phase II or III oncology clinical trial and had to be enrolled on this study prior to starting treatment for their primary malignant disease. Two groups of patients were entered on this study. Patients at least 18 years old and less than 50 years old were entered into a group considered young cancer patients, and patients at least 65 years old were entered into a group considered older adults. These two age groupings were selected to maximize the potential to demonstrate the effects of age on social support. Patients were enrolled between 7/16/1999 and $01 / 11 / 2002$. Accruing younger patients proved more difficult than expected, given the lower incidence rate of cancer in younger adults. Nationally, only about $13 \%$ of cancer patients are under the age of $50 .{ }^{24}$ At our institution, about twice as many patients age 65 or older go on phase II or III studies compared to patients less than age 50 . Accrual for this younger cohort was stopped at 20 because of the slow accrual rate.

\section{Measures}

\section{Lubben social network scale}

The Lubben Social Network Scale (LSNS) is a validated self-reported 10 item scale measuring embedded support, perceived support, and the reciprocation of support. ${ }^{25-28}$ All 10 items are highly intercorrelated (Cronbach's alpha $=0.70) .{ }^{29,30}$ Each question was scored on a zero to five scale with high scores indicating more social support. The overall LSNS social support score was calculated for each patient by summing the 10 questions. The LSNS was assessed at baseline before the patient started their cancer treatment. Our group recently used this same scale in a retrospective analysis of two lung cancer clinical trials to successfully demonstrate a lack of gender effect in social support among elderly patients. ${ }^{31}$ Differences in the individual LSNS questions were also analyzed.

\section{The uniscale overall quality of life scale}

The Uniscale ${ }^{32}$ tool used in this study was a single item visual analogue. Patients mark an ' $\mathrm{X}$ ' along a bar to indicate their overall QOL. The bar ranges from 'LOWEST QUALITY' on the left side of the bar to 'HIGHEST QUALITY' on the right side of the bar. The patient's score is the measured distance from the left of the bar to the ' $X$ ' divided by the total length of the bar times 100 . Scores then range from 0 to 100 with 100 being the best possible score. The UNISCALE has been validated in cancer clinical trials. ${ }^{33}$ The Uniscale was assessed at baseline (before the start of treatment) and weekly for the remaining four weeks of the study.

\section{The symptom distress scale}

The Symptom Distress Scale $(\mathrm{SDS})^{34}$ is a reliable and validated, self-reported 13-item questionnaire designed to identify physical and psychosocial symptoms of concern to patients and the degree of distress associated with each symptom. The scale has demonstrated convergent validity with the MOS-SF36 and discriminant validity has been established. ${ }^{35}$ The SDS was assessed at baseline (before the start of treatment) and weekly for the remaining four weeks of the study. For this and for all other patient-reported outcomes we translate scores onto a 0-100 point scale, where appropriate, so that higher scores always mean a positive indication for the patient (less pain or symptom distress, better quality of life).

\section{Analysis plan}

This prospective study compared social support, symptoms and QOL between the cohort of younger patients and the cohort of older patients. Secondary analyses included testing for gender differences. Fisher's exact tests were used to test for differences in discrete variables between groups. Kruskal-Wallis tests were used to test differences in continuous variables between the two age groups, 
Table I Baseline characteristics by age group

\begin{tabular}{|c|c|c|c|c|}
\hline & Age $<50(N=20)$ & Age $\geq 65(N=32)$ & Total $(\mathbf{N}=52)$ & $P$ value \\
\hline \multicolumn{5}{|l|}{ Age } \\
\hline Mean (SD) & $42.3(6.08)$ & $71.2(3.45)$ & $60.1(14.93)$ & NA \\
\hline Median & 44.0 & 71.0 & 69.0 & \\
\hline Range & 29 to 49 & 65 to 80 & 29 to 80 & \\
\hline \multicolumn{5}{|l|}{ Age group } \\
\hline 26 to 30 & I (5\%) & - & $\mathrm{I}(2 \%)$ & \\
\hline 31 to 35 & $3(15 \%)$ & - & $3(6 \%)$ & \\
\hline 36 to 40 & $3(15 \%)$ & - & $3(6 \%)$ & \\
\hline $4 I$ to 45 & $6(30 \%)$ & - & $6(12 \%)$ & \\
\hline 46 to 50 & 7 (35\%) & - & $7(13 \%)$ & \\
\hline 65 to 70 & - & $16(50 \%)$ & $16(31 \%)$ & \\
\hline 71 to 75 & - & $12(38 \%)$ & $12(23 \%)$ & \\
\hline 76 to 80 & - & $4(12 \%)$ & $4(8 \%)$ & \\
\hline Site & & & & 0.13 \\
\hline $\mathrm{Gl}$ & 7 (35\%) & I3 (4I\%) & $20(38 \%)$ & \\
\hline GU & $6(30 \%)$ & $4(13 \%)$ & $10(19 \%)$ & \\
\hline Lung & I (5\%) & $8(25 \%)$ & $9(17 \%)$ & \\
\hline Breast & $0(0 \%)$ & $2(6 \%)$ & $2(4 \%)$ & \\
\hline Other & $6(30 \%)$ & $5(16 \%)$ & II (2I\%) & \\
\hline Stage & & & & 0.77 \\
\hline Missing & 5 & I & 6 & \\
\hline Early (stage I, II) & I (5\%) & $2(7 \%)$ & $3(7 \%)$ & \\
\hline Late (stage III, IV) & 18 (95\%) & 25 (93\%) & $43(93 \%)$ & \\
\hline Gender & & & & 0.76 \\
\hline Female & $9(45 \%)$ & I3 (4I\%) & $22(42 \%)$ & \\
\hline Male & II (55\%) & 19 (59\%) & $30(58 \%)$ & \\
\hline Baseline QOL & & & & 0.36 \\
\hline Mean (SD) & $74.4(16.5)$ & $77.0(20.2)$ & $76.0(18.8)$ & \\
\hline
\end{tabular}

Kaplan-Meier curves and log-rank tests were used to compare survival between the groups, and Spearman correlations were used to determine associations between social support and symptoms. Changes in symptoms and QOL over time were tested by applying t-tests to the differences between baseline and week 4 values.

\section{Results}

Demographics

Table 1 shows baseline demographics between the older and younger cohort. The baseline demographics were similar between the two groups. Almost all (93\%) of the patients had late stage cancer.

\section{LSNS form completion}

During this 3-year period, 52 patients were enrolled in this study. Two patients did not provide any baseline information.
Out of the 50 patients with baseline information, $41(82 \%)$ filled out the LSNS. This completion percentage was sufficient to recommend the use of the LSNS in future studies of this patient population.

\section{Age differences in social support networks}

Table 2 and Figure 1 show LSNS by age group. There was no significant difference in overall mean LSNS by age (76.4 for younger patients, 80 for older patients, $P=0.49)$. However, contrary to the pre-study hypothesis, younger patients had lower levels of social support than older patients on individual Lubben questions. Patients in the younger group were more likely relied on by others on a daily basis $(69 \%$ vs $35 \%, P=0.04)$. Despite having advanced cancer, the younger patients had the added stress of being responsible for others. Patients $\geq 65$ years of age had more relatives they felt close to ( $85 \%$ vs $54 \%$ with $>4$ relatives, $P=0.017)$ and 
Table 2 Lubben Social Network Scale levels by age group

\begin{tabular}{|c|c|c|c|c|}
\hline & Age $<50(N=20)$ & Age $\geq 65(N=32)$ & Total $(\mathbf{N}=\mathbf{5 2})$ & $P$ value \\
\hline Lubben Social Network Score (0-100) & & & & 0.49 \\
\hline Mean & 76.4 & 80.0 & 78.7 & \\
\hline SD & 12.45 & 11.40 & $1 \mathrm{l} .77$ & \\
\hline
\end{tabular}

How many relatives do you see or hear from at least

once a month? (NOTE: Include in-laws with relatives)

0

I

2

$3-4$

5-8

9 or more

Tell me about the relative with whom you have the most contact. How often do you see or hear from that person?

Less than monthly

Monthly

A few times a month

Weekly

A few times a week

Daily

How many relatives do you feel close to? That is, how many of them do you feel at ease with, can talk to about private matters, or can call on for help?

0

I

2

3-4

5-8

9 or more

Do you have any close friends? That is, do you have friends with whom you feel at ease, can talk to about private matters, or can call on for help? If so, how many?

I

2

3-4

5-8

9 or more

How many of these friends do you see or hear from at least once a month?

0

I

2

$3-4$

$5-8$

9 or more

Tell me about the friend with whom you have the most contact. How often do you see or hear from that person?

Less than monthly

Monthly

$0 \%$

$0 \%$

$6 \%$

$33 \%$

$20 \%$

$7 \%$

$0 \%$

$0 \%$

$7 \%$

$13 \%$

$40 \%$

$40 \%$

$0 \%$

$0 \%$

$13 \%$

$33 \%$

$33 \%$

$20 \%$

$7 \%$

$7 \%$

$33 \%$

$33 \%$

$13 \%$

$7 \%$

$0 \%$

$14 \%$
$4 \%$

$0 \%$

$0 \%$

$12 \%$

$16 \%$

$68 \%$

0.67

$4 \%$

$0 \%$

$0 \%$

$12 \%$

$38 \%$

$46 \%$ 
Table 2 (Continued)

\begin{tabular}{|c|c|c|c|c|}
\hline & Age $<50(N=20)$ & Age $\geq 65(N=32)$ & Total $(\mathbf{N}=52)$ & $P$ value \\
\hline A few times a month & $7 \%$ & $8 \%$ & $8 \%$ & \\
\hline Weekly & $14 \%$ & $54 \%$ & $40 \%$ & \\
\hline A few times a week & $36 \%$ & $23 \%$ & $28 \%$ & \\
\hline Daily & $29 \%$ & $12 \%$ & $18 \%$ & \\
\hline $\begin{array}{l}\text { When you have an important decision to make, do you } \\
\text { have someone you can talk to about it? }\end{array}$ & & & & 0.25 \\
\hline Never & $0 \%$ & $0 \%$ & & \\
\hline Seldom & $0 \%$ & $0 \%$ & & \\
\hline Sometimes & $0 \%$ & $0 \%$ & & \\
\hline Often & $20 \%$ & $12 \%$ & & \\
\hline Very often & $7 \%$ & $0 \%$ & & \\
\hline Always & $73 \%$ & $88 \%$ & & \\
\hline $\begin{array}{l}\text { When other people you know have an important } \\
\text { decision to make, do they talk to you about it? }\end{array}$ & & & & 0.59 \\
\hline Never & $0 \%$ & $4 \%$ & $3 \%$ & \\
\hline Seldom & $0 \%$ & $0 \%$ & $0 \%$ & \\
\hline Sometimes & $20 \%$ & $24 \%$ & $23 \%$ & \\
\hline Often & $27 \%$ & $36 \%$ & $33 \%$ & \\
\hline Very often & $47 \%$ & $16 \%$ & $28 \%$ & \\
\hline Always & $7 \%$ & $20 \%$ & $15 \%$ & \\
\hline $\begin{array}{l}\text { Does anybody rely on you to do something for them } \\
\text { each day? For example: shopping, cooking dinner, doing } \\
\text { repairs, cleaning house, providing child care, etc? }\end{array}$ & & & & 0.04 \\
\hline No & $31 \%$ & $65 \%$ & $54 \%$ & \\
\hline Yes & $69 \%$ & $35 \%$ & $46 \%$ & \\
\hline $\begin{array}{l}\text { Do you help anybody with things like shopping, filling } \\
\text { out forms, doing repairs, providing child care, etc? }\end{array}$ & & & & 0.63 \\
\hline Never & $0 \%$ & $10 \%$ & $8 \%$ & \\
\hline Seldom & $17 \%$ & $25 \%$ & $23 \%$ & \\
\hline Sometimes & $67 \%$ & $40 \%$ & $46 \%$ & \\
\hline Often & $0 \%$ & $20 \%$ & $15 \%$ & \\
\hline Very often & $0 \%$ & $0 \%$ & $0 \%$ & \\
\hline Always & $17 \%$ & $5 \%$ & $8 \%$ & \\
\hline Do you live alone or with other people? & & & & 0.87 \\
\hline Live alone & $13 \%$ & $15 \%$ & $15 \%$ & \\
\hline Live with other unrelated individuals (eg, paid help) & $0 \%$ & $0 \%$ & $0 \%$ & \\
\hline Live with other relatives or friends & $13 \%$ & $8 \%$ & $10 \%$ & \\
\hline Live with spouse & $73 \%$ & $77 \%$ & $76 \%$ & \\
\hline
\end{tabular}

more friends they heard from monthly (85\% vs 54\% with $>2$ friends, $P=0.016$ ).

\section{Age differences in symptoms}

Figure 2 shows that older patients reported fewer symptoms than the younger patients. Older patients reported less overall symptom distress (mean of 86 vs $77, P=0.03$ ), less insomnia ( $11 \%$ vs $47 \%$ with frequent trouble sleeping, $P=0.003)$, better concentration ( $81 \%$ vs $40 \%$ with their normal ability to concentrate, $P=0.005$ ), better outlook ( $86 \%$ vs $40 \%$ with little or no worries, $P=0.01$ ), and less depression ( $74 \%$ vs $27 \%$ seldom feel depressed, $P=0.005)$.

\section{Social support levels and symptoms by gender}

There were no significant differences in overall social support levels by gender (mean overall LSNS scores of 81 for females vs 77 males, $P=0.40$ ). However, females 


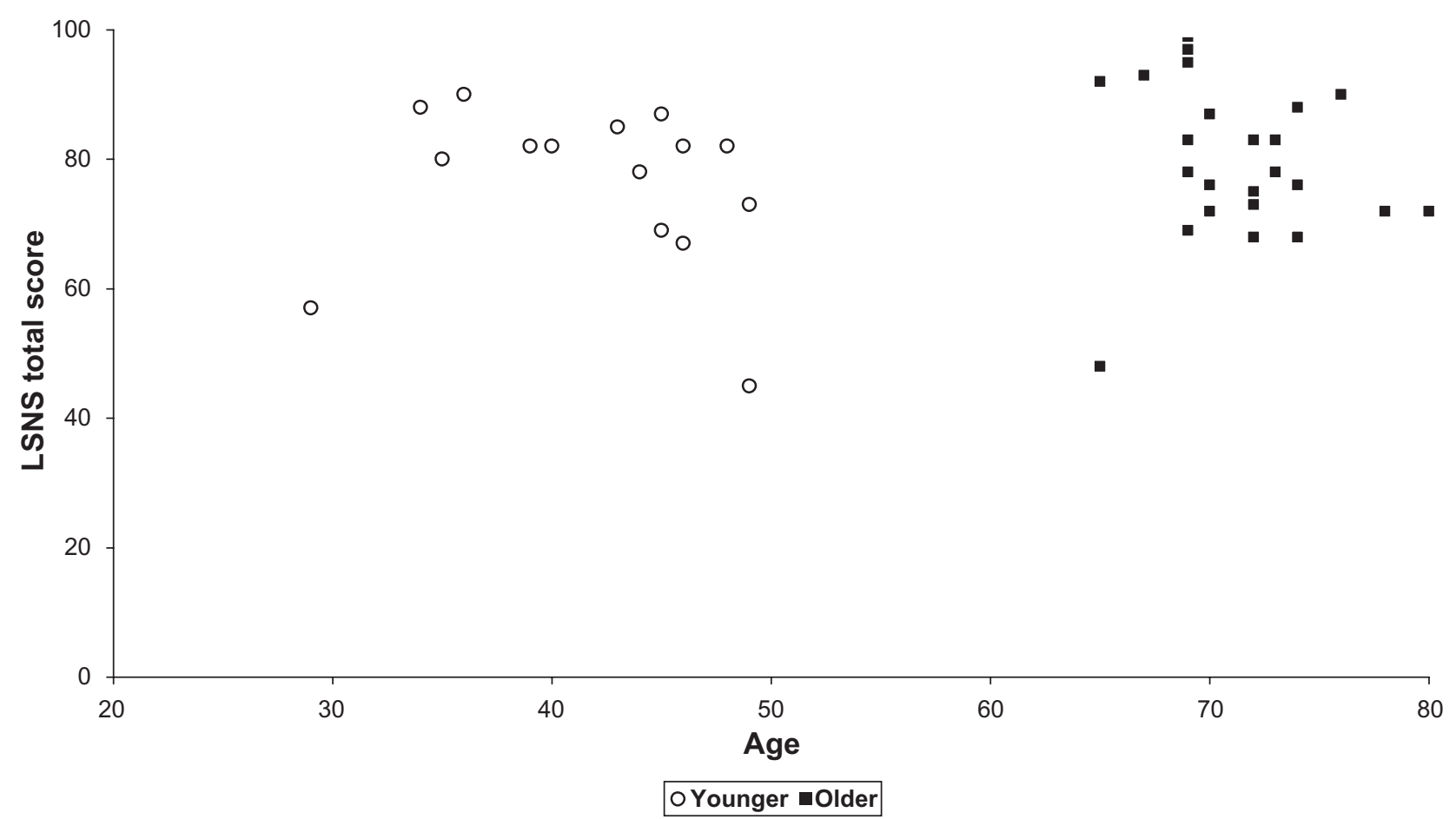

Figure I Age by total Lubben Social Network Scale (LSNS) score. Spearman correlation $=-0.05(P=0.78)$.

were more likely to see close relatives daily ( $70 \%$ vs $19 \%$, $P=0.0027)$ and were more likely to have other people discuss their problems with them (60\% of women reported "very often" or "always" compared to only $25 \%$ of men,
$P=0.02)$. Women reported more overall symptom distress at baseline (mean overall SDS score of 78 vs 86 for men, $P=0.02)$ and a higher frequency of SDS pain $(10 \%$ of women almost never had pain vs $59 \%$ of men, $P=0.005$ ).

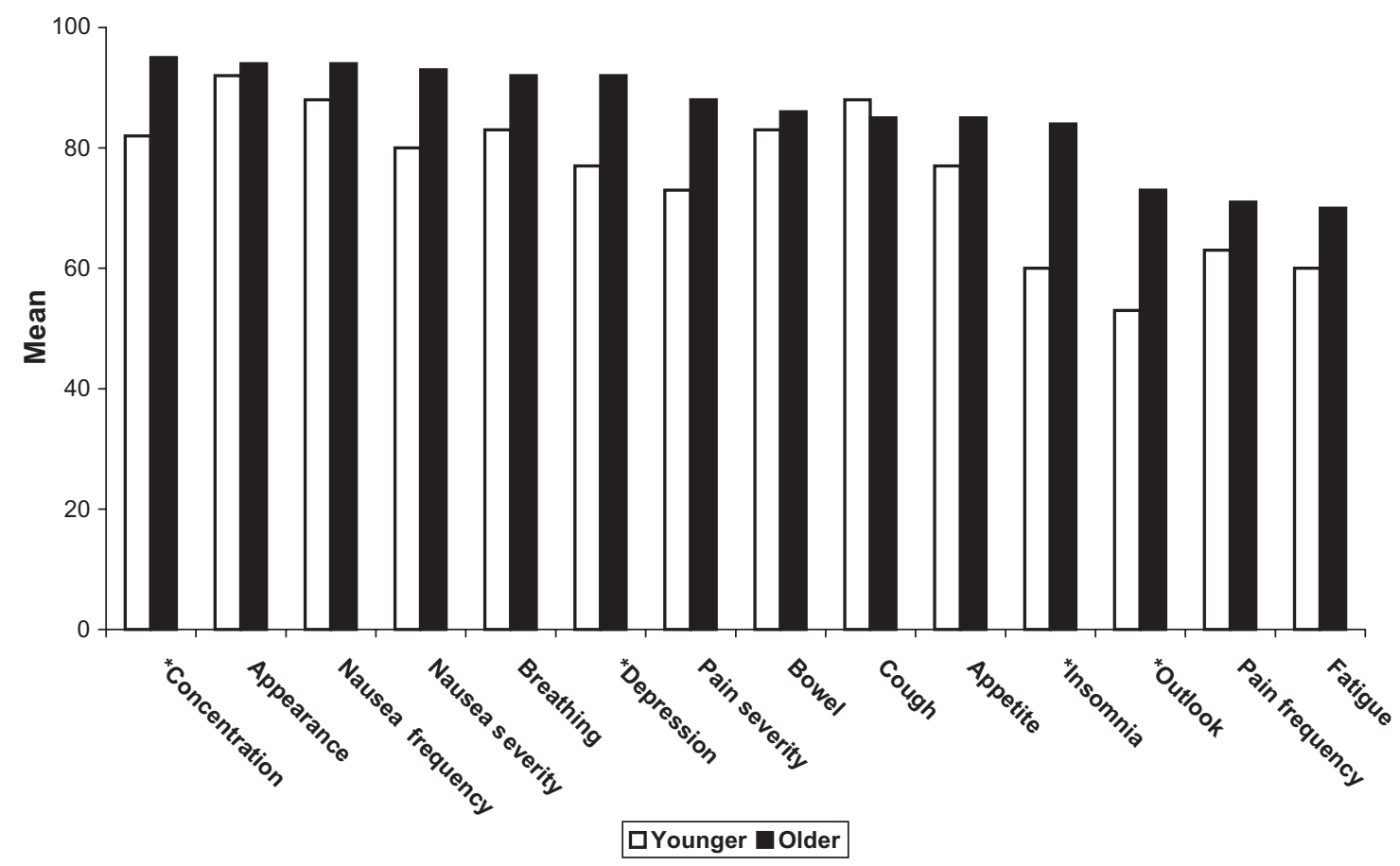

Figure 2 Mean baseline symptoms by age group.

*Indicates significant differences at $P<0.05$. 


\section{Age dfferences in QOL}

There were no statistically significant differences in baseline quality of life or changes in quality of life by age group or gender.

\section{Age differences in survival}

There were no statistically significant differences in survival times by age group (log-rank $P=0.98$ ). There was no a survival difference even after adjusting for stage of disease and gender (Cox model $P=0.60)$.

\section{Social support and survival}

Due to the small sample size and the lack of a survival difference, the two age cohorts were combined to explore the relationship between social support and survival. Some levels of the LSNS questions were also combined because of the sparse responses in some levels. As shown in Figure 3, always having someone to talk to about decisions was a significant predictor for survival even after adjusting for age and gender (Cox proportional hazard $P=0.01$, hazard ratio $=0.31,95 \%$ confidence interval for the odds ratio of 0.002 to 0.492 ). For this analysis, patients with responses of 'often' and 'very often' were combined and compared to patients responding with 'always'.

\section{Correlations between social support and symptoms}

There was a modest correlation between symptoms and how often they saw their closest friend $(-0.50$ correlation with overall SDS, and 0.51 correlation with fatigue).

\section{Changes in symptoms and QOL over time.}

There were no significant differences in the changes in symptoms or QOL over time by age group. The combined cohort of patients in both age groups showed a significant decrease in QOL over time (mean decrease of 7.9, $P=0.02$ ), a decrease in pain frequency (mean improvement of $0.4, P=0.02$ ), and a decrease in SDS outlook (mean decrease $-0.3, P=0.04$ ).

\section{Discussion}

Social support networks are important factors in the health of the elderly. ${ }^{36,37}$ Better social support networks have been linked with patient survival, overall health, their ability to carry out routine daily tasks, and their ability to cope with major life events and disease. ${ }^{5,38-40}$ Patients can become very isolated after a cancer diagnosis due to the social stigma associated with cancer, but this is the time these patients need the most support, and their level of support is associated with outcome. Recent evidence has emerged that both supports the importance of social networks on

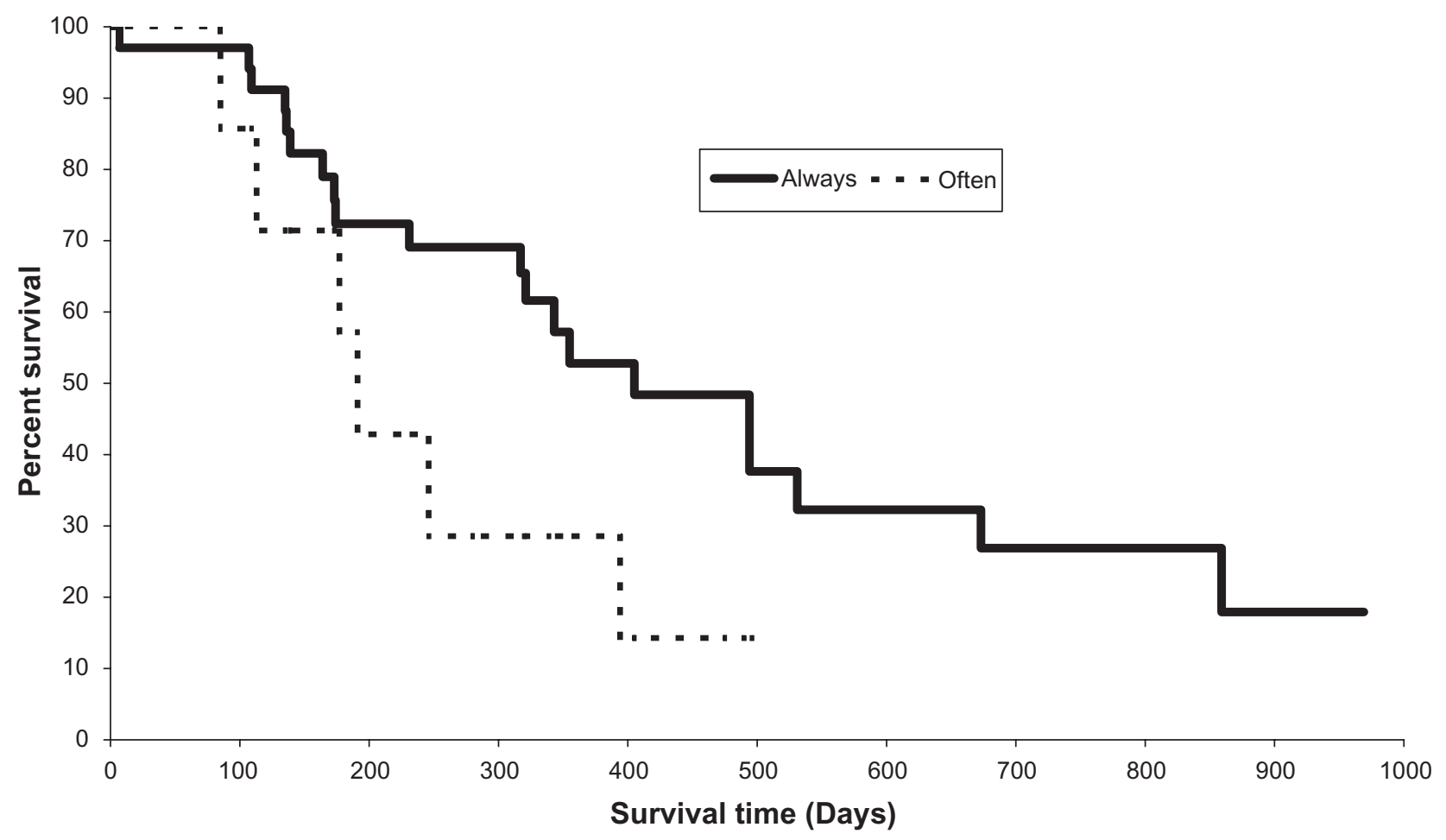

Figure 3 Overall survival by having someone to discuss issues. 
health ${ }^{41,42}$ and challenges the notion that older adults are more isolated. ${ }^{43}$

This study suggests there may be a generational gap in the level of social support experienced by cancer patients. In this study, younger patients tended to have smaller support networks and fewer close friends. Younger patients also reported higher levels of symptoms. These results were in perfect opposition to our research hypothesis. The reasons for these results should be explored further. It is possible that the younger patients do not have a spouse or partner to lean on or their parents or other family members around for support. Their friends are younger and may be busy with their own careers and families. The rapid growth of internet social networks may also have resulted in an increase in the size of social networks, but a decrease in face-to-face social skills and therefore less direct social networking among younger adults. The effects of internet networking on cancer patients, requires further investigation. It is also possible that older patients had developed social networks as they aged in response to previous illness and disability and that these established social networks were maintained. Younger patients would be less likely to have developed and maintained similar social networks. The younger patients also were more likely to be relied on by others on a daily basis. This likely meant the patients had the added burden of dealing with how their cancer will affect their young children or a spouse.

Age group and gender were not significant factors for survival in this study. These results are not terribly surprising in that the impact of age group ${ }^{44,45}$ and gender ${ }^{46,47}$ on survival is variable across patient populations and clinical studies. However, there was some evidence that having someone to discuss decisions with and being able to see friends and relatives often was linked to longer survival. This is an intriguing result that requires further investigation.

This study suggests that cancer patients may benefit from a system that fosters positive, supportive social networks. Social networking with close trusted friends and relatives should be encouraged, as these interactions promote improved quality of life and longer survival. Cancer health providers should be aware of the potential for social isolation and its effects on cancer patients. ${ }^{48}$ Future interventions could include screening for insufficient social networks, enhancing and encouraging existing social networks, and connecting isolated patients to potential social links. The quality of these social networks also needs to be considered. Social supports need to be positive, supportive and tailored to the individual.
A methodological note from this study indicates that the LSNS was easy for participants to complete and provided reasonably detailed data on the relative well-being of patient social networks. In particular, the use of individual item analysis provided supplementary insights that could not be garnered from the total score. This is a phenomenon that has been seen in other studies and is a particular focus of the research program of the senior author. ${ }^{49,50}$ These findings have supported the examination of results for individual items within a summated score since changes in individual items may be lost among the summated scores of multi-item assessments.

A limitation of this study is that the patients were all from cancer clinical trials. Patients going on clinical trials are only a small fraction of all cancer patients and they may have higher levels of support than other patients. Higher levels of support are likely needed for patients on clinical trials to support the extra trips and expenses. The findings may be magnified in patients not able to participate in a clinical trial.

\section{Future research}

The data suggest that social networks can be successfully evaluated in cancer patients. More definitive studies are needed into the differences in social support networks between age groups, the impact of social networks on patient outcomes, and the impact of identifying and alleviating social isolation. Future plans include testing an intervention targeted at improving social networks in patients identified as having low social support. A "menu" of support services will be assembled by the investigators and provided to patients to see if patients that receive structured, active encouragement and information from an enhanced social network will report higher QOL, fewer symptoms, and improved toxicity profiles. Future studies will also include patients in the middle age group (50 to 64$)$.

\section{Acknowledgment of financial support}

This study was conducted as a collaborative trial of the Mayo Clinic and was supported in part by Public Health Service grants CA-25224, CA-37404, CA-63848, CA-63849, and CA-35195. The authors report no conflicts of interest in this work.

\section{Disclosures}

The authors report no conflicts of interest in this work. 


\section{References}

1. Surveillance, Epidemiology, and End Results (SEER) Program (www. seer.cancer.gov). Prevalence database: "US Estimated 29-Year L-D Prevalence Counts on 1/1/2004 by Duration". National Cancer Institute, DCCPS, Surveillance Research Program, Statistical Research and Applications Branch, released 2007, based on the 2006 SEER data submission.

2. Chapple A, Ziebland S, McPherson A. Stigma, shame, and blame experienced by patients with lung cancer: qualitative study. $B M J$. $2004 \mathrm{~J} ; 328(7454): 1470$.

3. Norbeck JS. Social Support: A model for clinical research and application. Adv Nurs Sci. 1981;3(4):43-59.

4. Ryan LS. Psychosocial issues and lung cancer: A behavioral approach. Semin Oncol Nurs. 1996;12(4):318-323.

5. Ceria CD, Masaki KH, Rodriguez BL, Chen R, Yano K, Curb D. The relationship of psychosocial factors to total mortality among older Japanese-American men: The Honolulu Heart Program. J Am Geriatr Soc. 2001;49(6):725-731.

6. Rutledge T, Matthews K, Lui LY, Stone KL, Cauley JA. Social networks and marital status predict mortality in older women: prospective evidence from the Study of Osteoporotic Fractures (SOF). Psychosom Med. 2003;65(4):688-694.

7. Mistry R, Rosansky J, McGuire J, McDermott C, Jarvik L. UPBEAT Collaborative Group. Social isolation predicts re-hospitalization in a group of older American veterans enrolled in the UPBEAT Program. Unified Psychogeriatric Biopsychosocial Evaluation and Treatment. Int J Geriatr Psychiatry. 2001;16(10):950-959.

8. Nosarti C, Roberts JV, Crayford T, McKenzie K, David AS. Early psychological adjustment in breast cancer patients: a prospective study. $J$ Psychosom Res. 2002;53(6):1123-1130.

9. Crooks VC, Lubben J, Petitti DB, Little D, Chiu V. Social network, cognitive function, and dementia incidence among elderly women. $\mathrm{Am}$ J Public Health. 2008;98(7):1221-1227.

10. Baker AC. The spouse's positive effect on the stroke patient's recovery. Rehabil Nurs. 1993;18(1):30-33.

11. Carlsson J, Hamrin E. Psychological and psychosocial aspects of breast cancer treatment. A literature review. Cancer Nurs. 1994;17(5): 418-428.

12. Dow KH. A review of late effects of cancer in women. Semin Oncol Nurs. 1995;11(2):128-136.

13. Suominen T, Leino-Kilpi H, Laippala P. Who provides support and how? Breast cancer patients and nurses evaluate patient support. Cancer Nurs. 1995;18(4):278-285.

14. Akechi T, Okamura H, Yamawaki S, et al. Predictors of patients' mental adjustment to cancer: patient characteristics and social support. $\mathrm{Br} J$ Cancer. 1998;77(12):2381-2385.

15. Guidry JJ, Aday LA, Zhang D, et al. The role of informal and formal social support networks for patients with cancer. Cancer Pract. 1997;5(4):241-246.

16. Helgeson VS, Cohen S. Social support and adjustment to cancer: reconciling descriptive, correlational, and interventional research. Health Psychol. 1996;15(2):135-148.

17. Courtens AM, Stevens FC, Crebolder HF, et al. Longitudinal study on quality of life and social support in cancer patients. Cancer Nurs. 1996;19(3):162-169.

18. Kaplan KM, Weinberg GB, Small A, et al. Breast cancer screening among relatives of women with breast cancer. Am J Public Health. 1991;81(9):1174-1179.

19. Lugton J. The nature of social support as experienced by women treated for breast cancer. J Adv Nurs. 1997;25(6):1184-1191.

20. Dunkel-Schetter C, Wortman C. The interpersonal dynamics of cancer: Problems in social relationships and their impact on the patients. In: Friedman HS, DiMatteo MR, editors. Interpersonal Issues in Health Care. New York: Academic Press, 1982:69-100.

21. Krishnasamy M. Social support and the patient with cancer: a consideration of the literature. $J A d v$ Nurs. 1996;23(4):757-762.

22. Bottomley A, Jones L. Social support and the cancer patient-A need for clarity. Eur J Cancer Care. 1997;6(1):72-77.
23. Cohen J. Statistical Power Analysis for the Behavioral Sciences (2nd Edition). Lawrence Erlbaum Associates, Inc. Hillsdale, New Jersey, 1988.

24. National Cancer Institute. http:/seer.cancer.gov/faststats.

25. Lubben JE. Family and Community Health. 1988;11(3):42-52.

26. Lubben J, Gironda M, Measuring social networks and assessing their benefits. In Social Networks and Social Exclusion: Sociological and Policy Perspectives. Eds Phillipson, Allan, Morgan, Ashgate. 2004.

27. Lubben JE. Assessing social networks among elderly populations. Journal of Family and Community Health. 1988;11:42-52.

28. Lubben JE, Weiler PG, Chi I. Health practices of the elderly poor. Am J Public Health. 1989;79(6):731-734.

29. Nahm E, Resnick B, Gaines J. Testing the reliability and validity of computer-mediated social support measures among older adults: A pilot study. Comput Inform Nurs. 2004;22(4):211-219.

30. Yu DSF, Lee DTF, Woo J. Psychometric testing of the Chinese version of the Medical Outcomes Study Social Support Survey (MOS-SSS-C). Res Nurs Health. 2004;27(2):135-143.

31. Jatoi A, Hillman SL, Allen Ziegler KL, Stella PJ, Soori GS, Rowland KM Jr. Is social support associated with improved clinical outcomes in geriatric lung cancer patients? Observations from North Central Cancer Treatment Group Studies N9921 and N0222. Cancer Manag Res. 2009;1:61-68.

32. Spitzer WO, Dobson AJ, Chesterman E, et al. Measuring the quality of life of cancer patients: a concise QL-index for use by physicians. J Chronic Dis. 1981;34(12):585-597.

33. Sloan JA, Loprinzi CL, Kuross SA, et al. Randomized comparison of four tools measuring overall quality of life in patients with advanced cancer. J Clin Oncol. 1998;16 (11):3662-3673.

34. McCorkle R, Young K. Development of a symptom distress scale. Cancer Nurs. 1978;1(5):373-378.

35. Moinpour CM, Feigl P, Metch B, et al. Quality of life end points in cancer clinical trials: review and recommendations. J Natl Cancer Inst. 1989;81(7):485-495.

36. Lubben J, Gironda M. Centrality of social ties to the health and well-being of older adults. In: Berkman B, Harootyan L, Editors. Social Work and Health Care in an Aging Society. Springer Publishing Company. 2003.

37. Tremethick MJ. Thriving, not just surviving. The importance of social support among the elderly. J Psychosoc Nurs Ment Health Serv. 1997;35(9):27-31.

38. Rubinstein RL, Lubben JE, Mintzer JE. Social isolation and social support: And applied perspective. J Appl Gerontol. 1994;13(1):58-72.

39. House JS. Work, Stress, and Social Support. Addision Wesley, Reading, Massachusetts, 1981.

40. Mor-Barak ME, Miller LS. A longitudinal study of the causal relationship between social networks and health of the poor frail elderly. J Appl Gerontol. 1991;10(3):293-310.

41. Cacioppo JT, Hawkley LC. Social isolation and health, with an emphasis on underlying mechanisms. Perspect Biol Med. 2003;46(3 Suppl):S39-S52.

42. Cacioppo JT, Hughes ME, Waite LJ, Hawkley LC, Thisted RA. Loneliness as a specific risk factor for depressive symptoms: crosssectional and longitudinal analyses. Psychol Aging. 2006;21(1): 140-151.

43. Cornwell EY, Waite LJ. Measuring social isolation among older adults using multiple indicators from the NSHAP study. J Gerontol Social Sciences. 2009;64B(S1):i38-i46.

44. Domingo E, Surinach JM, Murillo J, et al. Prognostic factors in the diagnostic work-up of cancer patients in an internal medicine department: does age matter? Int J Clin Pract. 2008;62(11): $1723-1729$.

45. Levi F, Randimbison L, Vecchia CL. Breast Cancer Survival in Relation to Sex and Age. Oncology. 1992;49(6):413-417.

46. International Early Lung Cancer Action Program Investigators, Henschke CI, Yip R, Miettinen OS. Women's susceptibility to tobacco carcinogens and survival after diagnosis of lung cancer. JAMA. 2006;296(2):180-184. 
47. Hendifar A, Yang D, Lenz F, et al. Gender Disparities in Metastatic Colorectal Cancer Survival. Clin Cancer Res. 2009;15(20): 6391-6397.

48. Tremethick MJ. Alone in a crowd: A study of social networks in home health and assisted living. J Gerontol Nurs. 2001;27(5):42-47.

49. Sloan JA, Aaronson N, Cappelleri JC, et al. Assessing the clinical significance of single items relative to summated scores. Mayo Clin Proc. 2002;77(5):479-487.
50. Sloan JA, Berk L, Roscoe J, et al. National Cancer Institute. Integrating patient-reported outcomes into cancer symptom management clinical trials supported by the National Cancer Institute-sponsored clinical trials networks. J Clin Oncol. 2007;25(32):5070-5077.

\section{Publish your work in this journal}

Cancer Management and Research is an international, peer-reviewed open access journal focusing on cancer research and the optimal use of preventative and integrated treatment interventions to achieve improved outcomes, enhanced survival and quality of life for the cancer patient. The journal welcomes original research, clinical \& epidemiological studies, reviews \& evaluations, guidelines, expert opinion \& commentary, case reports \& extended reports. The manuscript management system is completely online and includes a very quick and fair peerreview system, which is all easy to use. Visit http://www.dovepress.com/ testimonials.php to read real quotes from published authors.

Submit your manuscript here: http://www.dovepress.com/cancer-management-and-research-journal 